\title{
Limitations of xylose tolerance test as a screening procedure in childhood coeliac disease
}

\author{
S. P. LAMABADUSURIYA, S. PACKER, and J. T. HARRIES \\ From The Hospital for Sick Children and Institute of Child Health, London
}

\begin{abstract}
Lamabadusuriya, S. P., Packer, S., and Harries, J. T. (1975). Archives of Disease in Childhood, 50,34. Limitations of xylose tolerance test as a screening procedure in childhood coeliac disease. The usefulness of the xylose tolerance test as a screening procedure for coeliac disease has been reassessed in 54 children with suspected coeliac disease. 5- and 24-hour urinary excretion rates of xylose were of no value in discriminating between patients with and without coeliac disease; similarly, the 3-hour blood xylose concentration was nondiscriminatory.

Three $(15 \cdot 8 \%)$ patients with subtotal villous atrophy and $8(61.5 \%)$ with partial villous atrophy due to coeliac disease had one-hour blood xylose values which fell within the normal range. The effect of withdrawal or reintroduction of dietary gluten on sequential one-hour blood xylose levels was variable and generally unhelpful in predicting those patients who developed gluten-induced mucosal changes.

The results of the present study emphasize the serious limitations of the xylose tolerance test as a screening procedure in childhood coeliac disease. It is recommended that the use of the urinary xylose test should be abandoned in the paediatric population. A normal one-hour blood xylose value does not exclude a diagnosis of coeliac disease even in young children who have never received a glutenfree diet. A clinical suspicion of coeliac disease remains the most important single factor in deciding whether to perform a jejunal biopsy.
\end{abstract}

The quantification of urinary excretion rates and/or blood concentrations of $D$-xylose after an oral load is widely used as a screening procedure for coeliac disease and other malabsorptive states (Benson et al., 1957; Christiansen, Kirsner, and Ablaza, 1959; Fowler and Cooke, 1960; Chanarin and Bennett, 1962; Hubble and Littlejohn, 1963; Finlay, Hogarth, and Wightman, 1964; Hawkins, 1970), but the limitations of this test in adult patients have recently been emphasized by Sladen and Kumar (1973). In a recent report, however, Rolles et al. (1973) applied the one-hour blood xylose screening test to children with suspected coeliac disease, and presented data which showed an exceptional degree of discrimination between children with and without coeliac disease.

In true coeliac disease the intolerance to gluten is a permanent phenomenon (Mortimer et al., 1968; Sheldon, 1969; Young and Pringle, 1971; Hamilton and $M c N e i l l, 1972)$, and there may be an increased

Received 13 June 1974. risk of malignancy in affected cases (Harris et al., 1967; Barry and Read, 1973) which may be reduced by treatment with a gluten-free diet (Holmes et al., 1974). The application of strict diagnostic criteria is thus of paramount importance to the child and family.

This paper presents the results of a study designed to reassess the usefulness of the xylose tolerance test with particular reference to the one-hour blood xylose levels. Preliminary results of the study have been published in abstract form (Lamabadusuriya, Packer, and Harries, 1974).

\section{Patients and methods}

Patients. A total of 68 jejunal biopsies were performed in 54 patients with suspected coeliac disease. In all but 9 instances xylose tolerance tests were performed within 48 hours of the biopsy and in the children receiving a normal diet, dietary intake of wheat protein was at least $5 \mathrm{~g} /$ day immediately before the test. On the basis of mucosal appearance on light microscopy and response to a gluten-free diet (GFD), 14 patients 
who had never received a GFD and 4 patients who had previously received a GFD and subsequently returned to a gluten-containing diet (GCD) were shown to have coeliac disease; 15 patients who had received a GFD for periods ranging from 1 to 13 years were biopsied before and during a 2 - to 7 -month gluten challenge $(10 \mathrm{~g}$ wheat protein/day); 15 patients receiving a GCD had normal biopsies and no other evidence of malabsorption; 6 patients had mucosal abnormalities due to causes other than coeliac disease. The xylose tolerance tests have been grouped according to the appearance of the jejunal mucosa by light microscopy: group 1 normal while receiving a GCD; group 2 normal while receiving a GFD; group 3 subtotal villous atrophy while receiving a GCD; group 4 partial villous atrophy while receiving a GCD; group 5 other mucosal abnormalities not due to coeliac disease (e.g. tropical sprue, iron deficiency anaemia). Further details of the groups are shown in the Table.

\section{TABLE}

Details of groups of patients investigated

\begin{tabular}{c|c|rc|rr}
\hline \multirow{2}{*}{ Group } & \multirow{2}{*}{$\begin{array}{c}\text { No. of } \\
\text { biopsies }\end{array}$} & \multicolumn{2}{|c|}{$\begin{array}{c}\text { Age (yr) } \\
\text { (mean) }\end{array}$} & \multicolumn{2}{|c}{ Weight (kg) } \\
(range) & (mean) & (range) \\
\hline 1 & 19 & $6 \cdot 6$ & $0 \cdot 7-15 \cdot 3$ & $18 \cdot 5$ & $7 \cdot 0-57 \cdot 3$ \\
2 & 12 & $10 \cdot 2$ & $4 \cdot 0-15 \cdot 2$ & $32 \cdot 6$ & $17 \cdot 9-60 \cdot 0$ \\
3 & 19 & $4 \cdot 7$ & $0 \cdot 6-16 \cdot 4$ & $16 \cdot 5$ & $4 \cdot 7-57 \cdot 2$ \\
4 & 12 & $10 \cdot 2$ & $4 \cdot 3-15 \cdot 4$ & $31 \cdot 9$ & $18 \cdot 1-60 \cdot 0$ \\
5 & 6 & $5 \cdot 9$ & $0 \cdot 4-8 \cdot 7$ & $17 \cdot 9$ & $4 \cdot 0-25 \cdot 1$ \\
& & & & & \\
\hline
\end{tabular}

Methods. All tests were performed after a 9-hour fast except in infants under the age of 1 year when the fast was 5 hours. Administration of D-xylose $(0.4 \mathrm{~g} / \mathrm{kg}$ body weight up to a maximum dose of $7.5 \mathrm{~g}$ in water so as to provide a $3 \%$ solution) was supervised by one of us (S.P.L. or S.P.) in all children tested; xylose` was of the highest purity (98-100\%). Whenever possible patients emptied their bladders immediately before the load and urine was collected into merthiolate bottles during the following 5 hours and subsequent 19 hours, and stored at $4{ }^{\circ} \mathrm{C}$. The fast was continued for 1 hour after the load, and $1 \mathrm{ml}$ venous blood was collected by S.P.L. or S.P. into fluoride bottles 1 and 3 hours after the load and stored at $4{ }^{\circ} \mathrm{C}$. None of the patients received any drugs for at least a week before the test, and in those patients receiving a normal diet gluten intake was adequate immediately before the test. Renal function (blood urea, urine microscopy, and protein) was normal in all patients tested.

Urine and blood xylose was measured by the method of Roe and Rice (1948), and all determinations were performed by S.P.L. in duplicate, the results being expressed as the mean value. The coefficient of variation for the assay in blood on 6 replicate estimations was $2 \%$, and for the tolerance test ( 5 one-hour blood xylose tests in a normal adult within a 30-day period) the coefficient was $7 \%$. Xylose concentrations in venous

\footnotetext{
$\star$ Sigma London Chemical Co. Ltd.
}

samples stored at $4{ }^{\circ} \mathrm{C}$ remained unchanged for up to 2 weeks from collection, and determinations were always performed within 1 week of collection.

Jejunal biopsies were performed under fluoroscopic control using a Crosby capsule, and mucosal specimens were taken from just distal to the ligament of Treitz.

\section{Results}

Urine xylose. The 5-and 24-hour urinary outputs of xylose expressed as a percentage of the administered dose are shown in Fig. 1. The values

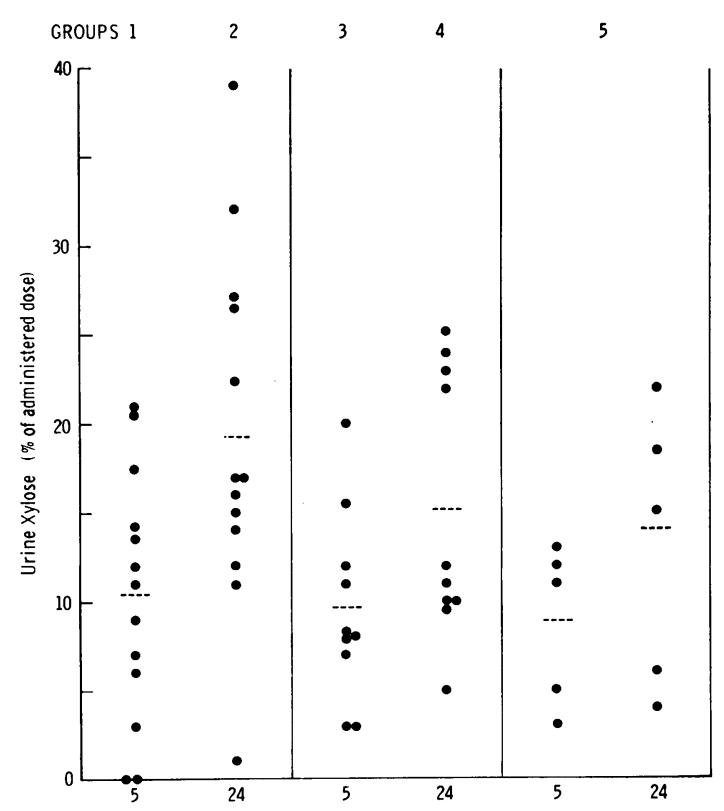

FIG. 1.-5- and 24-hour urinary outputs of xylose. All values expressed as percentage of administered dose. Values for groups 1 and 2 and groups 3 and 4 are plotted together. Broken line represents mean values.

for groups 1 and 2 and groups 3 and 4 are plotted together since there was no significant difference between data obtained from children with normal biopsies whether they were receiving a GCD or GFD; similarly results obtained from children with partial and with subtotal villous atrophy were similar. In patients with normal biopsies the mean and (range) for 5- and 24-hour urine xylose values were $10 \cdot 4(0-21)$ and $19 \cdot 2(1-39) \%$ of administered dose, respectively. In patients with mucosal abnormalities due to coeliac disease the 5- and 24-hour values all fell within the control range, as did the values for patients in group 5. 
Blood xylose. Figs. 2 and 3 show the one- and 3-hour blood xylose concentrations, respectively, in each of the 5 groups. There was no significant difference in the 3-hour blood xylose levels between any of the groups.

Since there was no significant difference in one-hour blood xylose levels between groups 1 and 2 , the values from both groups have been taken together and used as control data; in the 31 observations the range, mean, and standard error were $22 \cdot 5-54 \cdot 5,37 \cdot 0$, and $1 \cdot 3 \mathrm{mg} / 100 \mathrm{ml}$, respectively; the lowest value in the control range was similar to that calculated as being 2 SDs below the mean $(22 \cdot 4$ $\mathrm{mg} / 100 \mathrm{ml}) . \quad 3(15.8 \%)$ patients in group 3 , and 8 $(61.5 \%)$ in group 4 had one-hour blood xylose levels which fell well within the normal range; 2 of the patients in group 3 with normal values had never received a GFD, while the third patient developed subtotal villous atrophy during the gluten challenge;

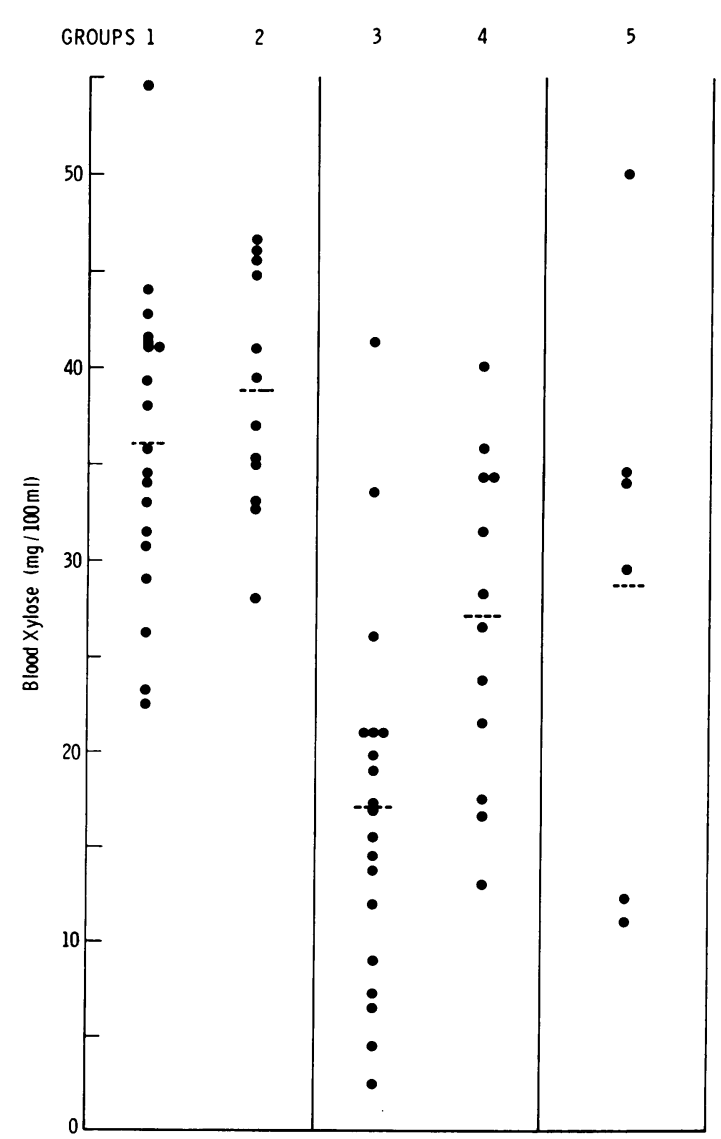

FIG. 2.-One-hour blood xylose concentrations ( $\mathrm{mg} / 100 \mathrm{ml}$ ). Broken line represents mean values.



FIG. 3.-3-hour blood xylose concentrations $(\mathrm{mg} / 100 \mathrm{ml}$ ). Broken line represents mean values.

all 3 children weighed less than $20 \mathrm{~kg}$. The abnormal result in group 5 was obtained in the patient with tropical sprue.

Effect of gluten withdrawal and reintroduction on one-hour blood xylose. Fig. 4 shows the short- and long-term effects of gluten reintroduction and withdrawal on sequential one-hour blood xylose levels in individual patients.

Within 5 days of instituting the gluten challenge blood xylose levels had increased in 2 out of 7 children; levels fell in the remaining 5 but in only 1 of these patients did the level reach the abnormal range. 4 of the 8 patients had normal blood xylose levels after gluten challenge for periods varying from 2-5 months, and in 1 of these the xylose value was similar to that found 2 days before challenge. 7 patients developed partial and 1 developed subtotal villous atrophy during the challenge period.

Within a few days of gluten withdrawl blood xylose increased in one patient and fell in the remaining 2; each of the 3 patients were newly diagnosed cases of coeliac disease.

\section{Discussion}

In addition to the transporting capacity of the mucosa, a variety of other factors will influence the concentration of xylose in blood and urine after an 

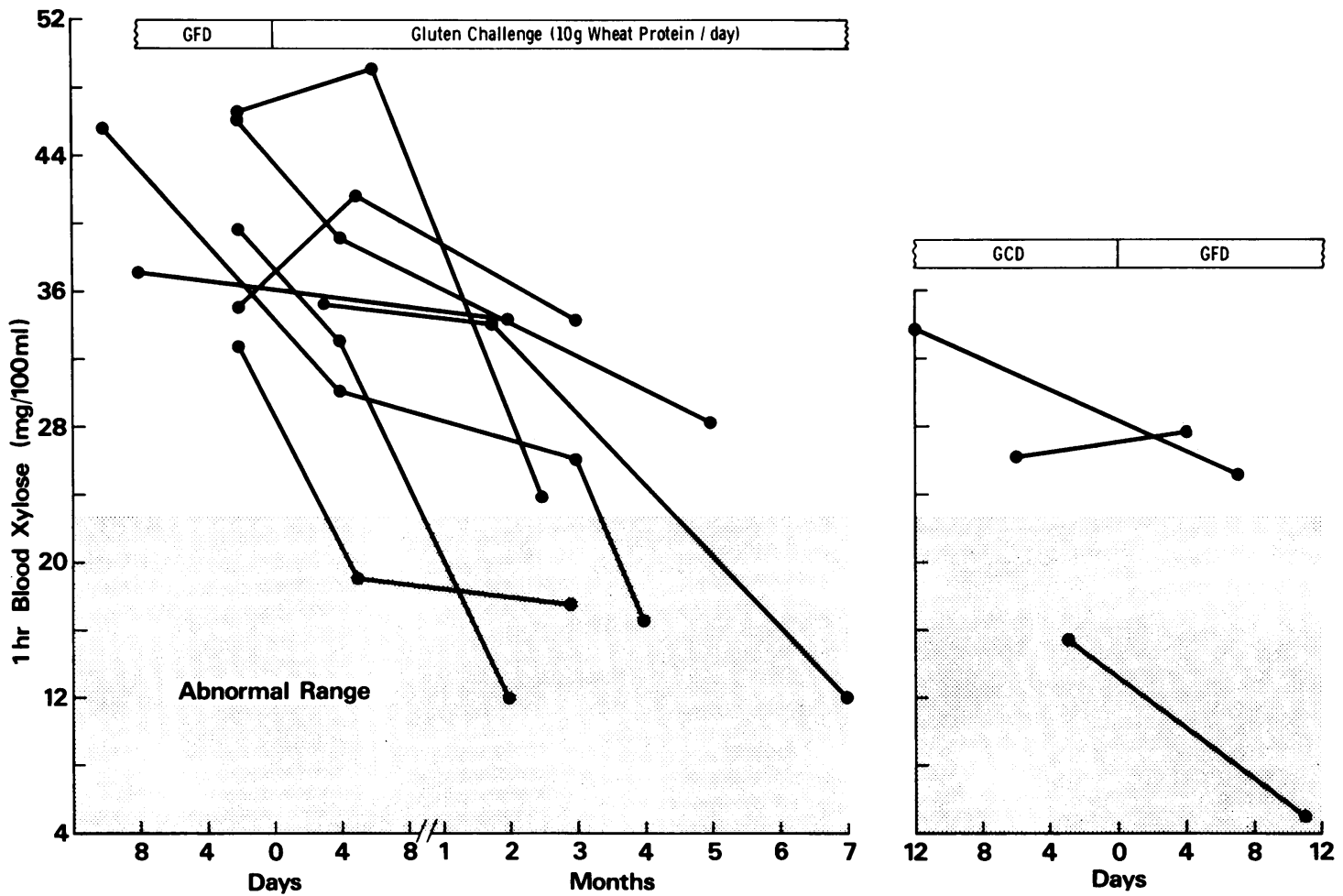

FIG. 4.-Short-and long-term effects of gluten reintroduction and withdrawal on sequential one-hour blood xylose concentrations $(\mathrm{mg} / 100 \mathrm{ml})$ in patients with proven coeliac disease. GFD and GCD indicate gluten-free diet and glutencontaining diet, respectively.

oral load, such as (i) the proportion of the load actually ingested, (ii) the load dose and the osmolarity of the solution, (iii) the rate of gastric emptying and thus the rate of delivery into the duodenum, (iv) intestinal transit, (v) intraluminal micro-organisms and drugs, and (vi) the rate of disappearance of the ingested xylose from the intravascular compartment into peripheral tissues and urine. It thus seems wise to interpret the results of xylose tolerance tests with caution in the assessment of mucosal structure and function, and the results of our study emphasize the limitations of this test even under the strict experimental design of the study. Administration of all loads was supervised by one of two people, the load solution was kept isosmolar (200 mOsm/l), drugs were withheld for at least a week before the test, patients with any evidence of renal dysfunction were discarded from the study, and all the chemical determinations were performed by the same person (S.P.L.). Despite these precautions, 5- and 24hour urinary excretion rates and 3-hour blood xylose concentrations proved useless in discriminating between children with and without coeliac disease. Accurate urine samples are obtained more easily from adults than small children, and Hawkins (1970) recommended that urinary xylose excretion should not be used as an investigatory procedure in children. We strongly support this view and are of the opinion that the use of the urinary xylose test should be abandoned in the paediatric population.

Hawkins (1970) suggested that determination of blood xylose one hour after a load might be useful as a screening test for children with suspected coeliac disease. His patient group, however, was small (7 children), and the author emphasizes the other factors which may affect blood xylose levels besides mucosal damage induced by gluten. Using the one-hour blood xylose test Rolles et al. (1973) showed an exceptional degree of discrimination between children with and without coeliac disease, and stated that 'a normal one-hour blood xylose level virtually excludes the diagnosis of coeliac disease in children below $30 \mathrm{~kg}$ '. $3(15 \cdot 8 \%)$ of our patients 
weighing less than $20 \mathrm{~kg}$ had one-hour blood xylose levels well within our normal control range, and in 2 of these children the levels were obtained at the initial diagnosis of coeliac disease. In their studies Rolles et al. (1973) gave a standard dose of $5 \mathrm{~g}$ xylose in $100-200 \mathrm{ml}$ of water so that the osmolarity range of the ingested solution would vary from 165 to 330 $\mathrm{mOsm} / \mathrm{l}$. The physiology of gastric emptying is complex and incompletely understood, but it is well established that the osmolarity of gastric and duodenal contents may have a marked effect on the rate of emptying (Hunt and Pathak, 1960; Elias et al., 1968; Meeroff, Go, and Phillips, 1973). Meeroff et al. showed that hyper- or hypotonic solutions delay gastric emptying compared with isotonic solutions. The patients in our study received hypotonic solutions $(200 \mathrm{mOsm} / \mathrm{l})$ which might have delayed gastric emptying rates. Since the solutions were kept isosmolar in all children tested, however, comparative data are valid.

Elias et al. (1968) studied the effects of solutions containing different concentrations of sugars on gastric emptying in young healthy adults, and showed that solutions of glucose and fructose in osmolarity ranges similar to those used by Rolles $e t$ al. (1973) had an appreciable effect; delay of gastric emptying rates was directly related to osmolarity. The children studied by Rolles et al. presumably received solutions of xylose with a wide range of osmolarity, and it is possible that in some of these delayed gastric emptying might have contributed to some of the low blood xylose levels reported, particularly in younger patients receiving small volumes $(100 \mathrm{ml})$ of xylose solutions with an osmolarity of $330 \mathrm{mOsm} / 1$. The authors consider some of the causes of 'false-low' results but do not state whether any of their patients were receiving any drugs before the test. This is of importance since a number of drugs such as aspirin, indomethacin, penicillin, neomycin, and tetracycline may affect absorption or renal clearance of xylose (Giorgi, 1970; Kendall, Nutter, and Hawkins, 1971).

The short- and long-term effects of gluten reintroduction or withdrawal on sequential one-hour blood xylose levels was also investigated in this study. In the 3 patients tested the short-term effects of gluten withdrawal on blood xylose was sufficiently variable to suggest that the test was unlikely to be of use in assessing any immediate therapeutic effect resulting from a gluten-free diet in newly diagnosed cases of coeliac disease. Our results were similarly disappointing in the patients who received a gluten challenge and in whom gluten-induced mucosal abnormalities developed. Strict diagnostic criteria have been recommended for childhood coeliac disease (Meeuwisse, 1970); these include the demonstration that gluten challenge induces mucosal abnormalities after a period of treatment with a gluten-free diet. The timing of diagnostic biopsies during gluten challenge is largely empirical particularly in those patients who remain asymptomatic, and our results indicate that the one-hour blood xylose test is unreliable in predicting when the biopsy should be performed.

Our results show that the one-hour blood xylose test has limitations as a screening procedure for suspected coeliac disease in children, both in newly diagnosed cases and in patients who return to a gluten-containing diet after a period of dietary treatment. A clinical suspicion of coeliac disease probably remains the most important single factor in deciding whether to perform a jejunal biopsy, even if the one-hour blood xylose level is normal. Our findings emphasize the importance of intestinal biopsy in the diagnosis of coeliac disease.

S.P.L. and S.P. gratefully acknowledge the British Council and The Wellcome Trust, respectively, for their generous support. We also thank the physicians who allowed us to study their patients.

\section{REFERENCES}

Barry, R. E., and Read, A. E. (1973). Coeliac disease and malignancy. Quarterly fournal of Medicine, 42, 665.

Benson, J. A., Jr., Culver, P. J., Ragland, S., Jones, C. M., Drummey, G. D., and Bougas, E. (1957). The D-xylose absorption test in malabsorption syndromes. New England Fournal of Medicine, 256, 335.

Chanarin, I., and Bennett, M. C. (1962). Absorption of folic acid and D-xylose as tests of small-intestinal function. British Medical fournal, 1, 985.

Christiansen, P. A., Kirsner, J. B., and Ablaza, J. (1959). D-xylose and its use in the diagnosis of malabsorptive states. American Fournal of Medicine, 27, 443.

Elias E., Gibson, G. J., Greenwood, L. F., Hunt, J. N., and Tripp, J. H. (1968). The slowing of gastric emptying by monosaccharides and disaccharides in test meals. Fournal of Physiology, 194, 317.

Finlay, J. M., Hogarth, J., and Wightman, K. J. R. (1964). A clinical evaluation of the D-xylose tolerance test. Annals of Internal Medicine, 61, 411.

Fowler, D., and Cooke, W. T. (1960). Diagnostic significance of D-xylose excretion test. Gut, 1, 67.

Giorgi, G. (1970). The effect of some drugs on p-aminohippurate and xylose transfer through isolated rat intestine. Pharmacological Research Communications, 2, 285.

Hamilton, J. R., and McNeill, L. K. (1972). Childhood celiac disease: response of treated patients to a small uniform daily dose of wheat gluten. Fournal of Pediatrics, 81, 885.

Harris, O. D., Cooke, W. T., Thompson, H., and Waterhouse, J. A. H. (1967). Malignancy in adult coeliac disease and idiopathic steatorrhoea. American fournal of Medicine, 42, 899.

Hawkins, K. I. (1970). Pediatric xylose absorption test: measurements in blood preferable to measurements in urine. Clinical Chemistry, 16, 749.

Holmes, G. K. T.; Stokes, P. L., McWalter, R., Waterhouse, J. A. H., and Cooke, W. T. (1974). Coeliac disease, malignancy, and gluten-free diet. (Abst.) Gut, 15, 339.

Hubble, D., and Littlejohn, S. (1963). The D-xylose excretion test in coeliac disease in childhood. Archives of Disease in Childhood, 38, 476. 
Hunt, J. N., and Pathak, J. D. (1960). The osmotic effects of some simple molecules and ions on gastric emptying. Fournal of Physiology, 154, 254.

Kendall, M. J., Nutter, S., and Hawkins, C. F. (1971). Xylose test: effect of aspirin and indomethacin. British Medical fournal, 1 , 533.

Lamabadusuriya, S. P., Packer, S., and Harries, J. T. (1974). Limitations of xylose tolerance test as screening procedure for coeliac disease. (Abst.) Archives of Disease in Childhood, 49, 244.

Meeroff, J. C., Go, V. L. W., and Phillips, S. F. (1973). Measurement of gastric emptying by duodenal aspiration: effects of intraduodenal osmolarity. Gastroenterology, 64, 770.

Meeuwisse, G. W. (1970). Round table discussion. Diagnostic criteria in coeliac disease. Acta Paediatrica Scandinavica, 59, 461.

Mortimer, P. E., Stewart, J. S., Norman, A. P., and Booth, C. C. (1968). Follow-up study of coeliac disease. British Medical fournal, 3, 7.
Roe, J. H., and Rice, E. W. (1948). A photometric method for the determination of free pentoses in animal tissues. Fournal of Biological Chemistry, 173, 507.

Rolles, C. J., Kendall, M. J., Nutter, S., and Anderson, C. M. (1973), One-hour blood-xylose screening-test for coeliac disease in infants and young children. Lancet, 2, 1043.

Sheldon, W. (1969). Prognosis in early adult life of coeliac children treated with a gluten-free diet. British Medical fournal, 2, 401.

Sladen, G. E., and Kumar, P. J. (1973). Is the xylose test still a worthwhile investigation? British Medical fournal, 3, 223.

Young, W. F., and Pringle, E. M. (1971). 110 children with coeliac disease, 1950-1969. Archives of Disease in Childhood, 46, 421.

Correspondence to Dr. J. T. Harries, Department of Child Health, Institute of Child Health, 30 Guilford Street, London WC1N 1EH. 